\title{
A diaphragmatic electrical activity-based optimization strategy during pressure support ventilation improves synchronization but does not impact work of breathing
}

Francois Beloncle ${ }^{1,2,3}$, Lise Piquilloud ${ }^{3,4}$, Nuttapol Rittayamai ${ }^{1,2,5}$, Christer Sinderby ${ }^{2}$, Hadrien Rozé ${ }^{6}$ and Laurent Brochard ${ }^{1,2^{*}}$

\begin{abstract}
Background: Poor patient-ventilator synchronization is often observed during pressure support ventilation (PSV) and has been associated with prolonged duration of mechanical ventilation and poor outcome. Diaphragmatic electrical activity (Eadi) recorded using specialized nasogastric tubes is a surrogate of respiratory brain stem output. This study aimed at testing whether adapting ventilator settings during PSV using a protocolized Eadi-based optimization strategy, or Eadi-triggered and -cycled assisted pressure ventilation (or PSV $N_{N}$ ) could (1) improve patient-ventilator interaction and (2) reduce or normalize patient respiratory effort as estimated by the work of breathing (WOB) and the pressure time product (PTP).

Methods: This was a prospective cross-over study. Patients with a known chronic pulmonary obstructive or restrictive disease, asynchronies or suspected intrinsic positive end-expiratory pressure (PEEP) who were ventilated using PSV were enrolled in the study. Four different ventilator settings were sequentially applied for 15 minutes (step 1: baseline PSV as set by the clinician, step 2: Eadi-optimized PSV to adjust PS level, inspiratory trigger, and cycling settings, step 3: step $2+$ PEEP adjustment, step 4: PSV $V_{N}$. The same settings as step 3 were applied again after step 4 to rule out a potential effect of time. Breathing pattern, trigger delay $\left(T_{d}\right)$, inspiratory time in excess $\left(T_{\text {iex }}\right)$, pressure-time product (PTP), and work of breathing (WOB) were measured th the end of each step.
\end{abstract}

Results: Eleven patients were enrolled in the study. Eadi-optimized PSV reduced $T_{d}$ without altering $T_{\text {iex }}$ in comparison with baseline PSV. PSV $V_{N}$ reduced $T_{d}$ and $T_{\text {iex }}$ in comparison with baseline and Eadi-optimized PSV. Respiratory pattern did not change during the four steps. The improvement in patient-ventilator interaction did not lead to changes in WOB or PTP.

Conclusions: Eadi-optimized PSV allows improving patient ventilator interaction but does not alter patient effort in patients with mild asynchrony.

Trial registration: Clinicaltrials.gov identifier: NCT 02067403. Registered 7 February 2014.

Keywords: Mechanical ventilation, Pressure support ventilation, Neurally adjusted ventilatory assist, Chronic pulmonary obstructive, Restrictive disease, Asynchrony

\footnotetext{
* Correspondence: brochardl@smh.ca

${ }^{1}$ Interdepartmental Division of Critical Care Medicine, University of Toronto,

Toronto, ON, Canada

${ }^{2}$ Keenan Research Centre and Li Ka Shing Knowledge Institute, St. Michael's

Hospital, 30 Bond St, Toronto, ON M5B 1W8, Canada

Full list of author information is available at the end of the article
} 


\section{Background}

Pressure support ventilation (PSV) is well tolerated [1] and has been helpful to reduce both adverse effects of prolonged sedation [2] and ventilator-associated diaphragmatic dysfunction $[3,4]$. Thus, it is widely used as soon as deep sedation and/or muscle paralysis and controlled mechanical ventilation are no longer required to oxygenate the patient. During PSV, each ventilator-delivered cycle is initiated by a flow or pressure variation (pneumatic signal) resulting from the patient's inspiratory effort. Pressurization is then delivered by the ventilator and lasts until a predetermined flow-based cycling-off criterion is reached. The amount of pressure delivered by the ventilator under PSV is constant and set by the clinician [5]. During PSV, the work of breathing (WOB) is shared between the patient and the ventilator. Due to differences in patients' and ventilators' respiratory profiles $[6,7]$, poor patient-ventilator synchronization is often observed $[8,9]$ and has been associated with abnormal WOB [10] and prolonged duration of mechanical ventilation $[8,11-13]$. A poor synchronization has been associated with suboptimal ventilator settings, especially over-assist [14], non-optimized expiratory cycling [7], and positive end-expiratory pressure (PEEP) setting [12, 15].

At the bedside, as no visual information on the patient's inspiratory activity is usually available on the ventilator screen, detecting patient-ventilator asynchronies is sometimes difficult even for experienced clinicians [16]. Diaphragmatic electrical activity (Eadi), used as a surrogate of respiratory brain stem output, recorded using specialized nasogastric tubes equipped with electrodes, can simplify the detection of patient-ventilator asynchronies and could be used to optimize the ventilator settings to improve the matching between the patient and the ventilator. Eadi signal can also be used in patients to deliver an assisted ventilation, synchronized and proportional to patient demand (NAVA mode) $[17,18]$. This study aimed at testing whether adapting ventilator settings (inspiratory trigger sensitivity, pressure support level, cycling-off criterion, and PEEP) during PSV using a protocolized Eadi-based optimization strategy or Eadi-triggered and -cycled assisted pressure ventilation (or neural PSV, $\mathrm{PSV}_{\mathrm{N}}$ ) could (1) improve patient-ventilator interaction and (2) modify patient's respiratory effort as estimated by the work of breathing (WOB) and the pressure time product (PTP) of the respiratory muscles in comparison with standard PSV.

\section{Methods}

This was a prospective cross-over study. It took place in the medical/surgical ICU of St Michael's hospital in Toronto, Canada, from March to October 2014. The trial was registered at clinicaltrials.gov (NCT 02067403).

\section{Patients}

Patients who were ventilated using PSV for an expected duration of ventilation of more than 24 hours and who had a known or suspected history of chronic pulmonary obstructive (COPD) or restrictive disease, obesity (defined as body mass index $\left.(\mathrm{BMI}) \geq 30 \mathrm{~kg} \cdot \mathrm{m}^{-2}\right)$, visible asynchronies or suspected intrinsic PEEP, were enrolled in the study. Exclusion criteria were contraindication to nasogastric tube placement, poor short-term prognosis or "Do not resuscitate" order already established and in palliative care.

\section{Data acquisition/physiological measurements}

At study inclusion, patients' demographic and medical characteristics, arterial blood gas analysis, Sequential Organ Failure Assessment (SOFA) score, Acute Physiology and Chronic Health Evaluation III (APACHE III) score, and baseline ventilator settings were recorded.

A specific nasogastric tube (Eadi catheter) equipped with electrodes and an esophageal balloon (Neurovent, Toronto, ON, Canada) was inserted. The Eadi catheter was connected to a Servo-I ventilator (Maquet, Solna, Sweden). Its position was controlled on the ventilator screen according to the manufacturer's instructions and previously published studies [19]. The calibration procedure of esophageal pressure (Pes) consisted of an occlusion test (or Baydur maneuver) (two to five inspiratory efforts) [20, 21].

A personal computer was connected to the ventilator. Flow, airway pressure (Paw), and Eadi waveforms were acquired from the ventilator using a dedicated software with a sampling frequency of $100 \mathrm{~Hz}$ (ServoTracker, Maquet, Solna, Sweden). Pes and Paw (measured between the $\mathrm{Y}$ piece of the ventilator circuit and the endotracheal tube) were recorded at $100 \mathrm{~Hz}$ by an analog/ numeric data-acquisition system (MP150, Biopac Systems, Goleta, CA, USA) connected to a second personal computer. All the aforementioned waveforms were continuously recorded for 5 minutes after a stabilization period of 10 minutes and were secondarily synchronized for offline analysis. Briefly, we synchronized both files to get the 0 flow point of the same respiratory cycle perfectly matched.

Trigger delay $\left(\mathrm{T}_{\mathrm{d}}\right)$ was defined as the time difference between the initial increase in Eadi (visually determined) and the beginning of the ventilator-delivered pressurization. Inspiratory time in excess $\left(\mathrm{T}_{\mathrm{iex}}\right)$ was calculated as the time difference between the time when Eadi decreased to $70 \%$ of peak Eadi and the end of ventilatordelivered pressurization (Additional file 1).

Five types of major patient-ventilator asynchronies (autotriggering, ineffective effort, double triggering, delayed cycling and premature cycling) as defined by Thille et al. [8] were determined by visual analysis from airway pressure, flow and Eadi curves over the 5 minutes recording period. Additionally, we computed during 
$\mathrm{PSV}_{\mathrm{N}}$ the number of pseudo-autotriggerings defined as a significant pressurization delivered by the ventilator ( $>50 \%$ of PEEP level) not related to a patient's effort [22]. Example of pseudo-autotriggerings is represented in Additional file 2.

The global asynchrony index was computed as the sum of the five types of major asynchronies but not pseudo-autotriggerings. Severe asynchrony was defined as a global asynchrony index greater than $10 \%[12,23]$.

The neuroventilatory efficiency (NVE) expresses the ability to generate volume normalized to neural drive and was defined as the ratio of tidal volume $(\mathrm{Vt})$ over peak of the Eadi (Eadi max $_{\text {mar }}$.

A semi-automated research software, described in previous works [24] was used for WOB and PTP measurements (SR program, non-commercially available, Barcelona, Spain).

WOB was determined from esophageal pressure measurement using the Campbell diagram as previously described [25].

PTP was obtained by measuring the area under the esophageal pressure signal between the onset of the inspiratory effort and the end of inspiration, defined as the end of inspiratory flow signal. This area was referenced to the chest wall static recoil pressure-time curve relationship [26].

For each step, respiratory rate (RR), tidal volume (Vt), minute ventilation, $\mathrm{T}_{\mathrm{d}}, \mathrm{T}_{\mathrm{iex}}, \mathrm{Eadi}_{\text {max }}$, area under the curve of the Eadi (Eadi ${ }_{\mathrm{AUC}}$ ), NVE, WOB and PTP were measured for the 25 initial breathing cycles during the recording period and were averaged.

\section{Study protocol}

Once the specific nasogastric tube was correctly positioned, four different ventilator settings corresponding to five sequential steps were applied for 10 minutes, followed by a recording period of 5 minutes for all conditions.

At inclusion, patients were ventilated with PSV as set by the attending physician and respiratory therapists in charge of the patient in order to target a respiratory rate between 20 and 30/minute and with a PEEP setting $\geq 5$ cmH2O (step 1).

Asynchronies were screened at the bedside using Paw, flow, and Eadi curves. The $T_{d}$ and $T_{\text {iex }}$ were estimated by freezing the screen and using cursors. During step 2, Eadi monitoring was used to sequentially optimize PS level, inspiratory trigger, and cycling settings to optimize patientventilator synchrony. In more detail, if ineffective efforts were observed, first the sensitivity of the inspiratory trigger was adapted to the lowest possible value without inducing auto-triggerings. Then, pressure support level was decreased as low as possible without inducing significant tachypnoea until ineffective efforts disappeared. Third, cycling-off criterion was gradually adjusted to decrease $\mathrm{T}_{\mathrm{iex}}$, based on Eadi signal visualization. If premature cyclings and/or double triggerings were present, insufflation time was gradually increased by decreasing the cycling-off criterion. During step 3a, Eadi signal was also used to adapt PEEP setting. Practically, if a prolonged $T_{d}$ was observed, PEEP was increased by a step of $1 \mathrm{~cm} \mathrm{H}_{2} \mathrm{O}$ until $\mathrm{T}_{\mathrm{d}}$ did not further decrease, up to a maximal value of $12 \mathrm{cmH}_{2} \mathrm{O}$. After this titration process, the PEEP value was selected as the lowest PEEP corresponding to the lowest $T_{d}$. During step 4, the ventilator was switched to $\operatorname{PSV}_{N}$. PSV $_{N}$ consisted of using the advantage of the triggering and cycling function of the neurally adjusted ventilatory assist (NAVA) mode but limiting the pressure to the same level than during PSV and using a high NAVA gain to create a square pressure wave. NAVA mode ventilation was thus set with the highest gain level $\left(15 \mathrm{cmH}_{2} \mathrm{O} / \mu \mathrm{V}\right)$ to provide very fast pressurization mimicking pressure support pressurization shape, to better match the initial inspiratory demand, which can be particularly high in the presence of respiratory distress $[27,28]$. The advantage of this mode would be to look very similar to clinicians used to pressure support ventilation but with an improved synchrony. The pressure limit was chosen to get the same level of assistance between step $3 \mathrm{a}$ and 4 .

The level of PEEP during step 4 was the same as during step 3a. After termination of step 4, the same settings as step 3a were applied again to rule out a potential effect of time (Step 3b).

\section{Statistical analysis}

As no previously published data allowed quantifying a benefit, no sample size calculation could be performed in this physiological study. Nonparametric tests were used because of the small number of patients. Sequentially, for each parameter, the absence of difference between steps $3 \mathrm{a}$ and $3 \mathrm{~b}$ were verified using Wilcoxon tests. The results of steps $3 \mathrm{a}$ and $3 \mathrm{~b}$ were considered together and the average values of the two steps are presented as step 3 . The measured parameters were compared across the different steps using nonparametric Friedman test. Wilcoxon tests were used to perform post hoc pairwise comparisons with correction for multiple comparisons using the false discovery rate approach. Statistical significance was defined as $p$ value $<0.05$. The statistical analysis was performed using Prism (GraphPad Software v5.0b, La Jolla, CA, USA).

\section{Results}

\section{Patient characteristics}

The study included 11 patients. The main characteristics at inclusion are detailed in Table 1. Six (55\%) patients had a medical history of chronic obstructive pulmonary disease (COPD). 
Table 1 Patient characteristics at inclusion

\begin{tabular}{|c|c|}
\hline Parameters & 11 patients \\
\hline Age (years) & $70(68-80)$ \\
\hline Sex M/F & $7 / 4$ \\
\hline Body mass index $\left(\mathrm{kg} \cdot \mathrm{m}^{-2}\right)$ & $25.4(22-30)$ \\
\hline \multicolumn{2}{|l|}{ Comorbidities } \\
\hline COPD & $6(55 \%)$ \\
\hline Obesity & $5(45 \%)$ \\
\hline Bronchiectasis & $1(9 \%)$ \\
\hline LV dysfunction & $1(9 \%)$ \\
\hline Interstitial pulmonary disease & $1(9 \%)$ \\
\hline APACHE III & $20(17-23.5)$ \\
\hline SOFA score total at inclusion & $5(3.5-8)$ \\
\hline respiratory & $2(1.5-3)$ \\
\hline cardiovascular & $1(0-2)$ \\
\hline neurologic & $0.5(0-1)$ \\
\hline hepatic & $0(0-0)$ \\
\hline hematologic & $0(0-1)$ \\
\hline renal & $1(0-1.5)$ \\
\hline \multirow[t]{6}{*}{ ICU admission diagnosis } & Acute respiratory failure 5 (45\%) \\
\hline & Stroke 2 (18\%) \\
\hline & Postoperative 1 (9\%) \\
\hline & Gastrointestinal bleeding 1 (9\%) \\
\hline & Cardiac arrest 1 (9\%) \\
\hline & Trauma 1 (9\%) \\
\hline Days from ICU admission & $9(2-15)$ \\
\hline $\begin{array}{l}\text { Days from initiation of } \\
\text { mechanical ventilation }\end{array}$ & $4(1-13)$ \\
\hline $\mathrm{pH}$ & $7.36(7.32-7.39)$ \\
\hline $\mathrm{PaO}_{2}(\mathrm{mmHg})$ & $102.5(83-133)$ \\
\hline $\mathrm{FiO}_{2}$ & $0.5(0.4-0.5)$ \\
\hline $\mathrm{PaO}_{2} / \mathrm{FiO}_{2}(\mathrm{mmHg})$ & $205(165-338)$ \\
\hline $\mathrm{PaCO}_{2}(\mathrm{mmHg})$ & $47(37.5-51.5)$ \\
\hline $\mathrm{HCO}_{3}-(\mathrm{mmHg})$ & $29(22.5-30.5)$ \\
\hline
\end{tabular}

Results are presented as median and interquartile range or number and percentage

COPD chronic obstructive pulmonary disease, $L V$ dysfunction left ventricular dysfunction, SOFA Sepsis-related Organ Failure Assessment, APACHE III Acute Physiology and Chronic Health Evaluation III

\section{Changes in ventilator settings during the study}

Ventilator settings during the four steps are mentioned in Table 2. Pressure support level was never modified. The inspiratory trigger sensitivity was increased in step 2 in comparison with step 1 in five patients (45\%). It was not modified in six patients (55\%). Cycling-off criterion was higher in step 2 than in step 1 in eight patients $(73 \%)$, was lower in one patient $(9 \%)$ and was not modified in two patients (18\%). PEEP level was increased from step 2 to step 3 in four patients (36\%) and was not modified in seven patients (64\%).

\section{Effect of PSV optimization and PSV $\mathrm{N}_{\mathrm{N}}$ on synchronization} Eadi-optimized PSV (step 3) allowed reducing $\mathrm{T}_{\mathrm{d}}$ in comparison with standard PSV (step 1) (Fig. 1 and Additional file 3). The $\mathrm{T}_{\mathrm{d}}$ was shorter in $\mathrm{PSV}_{\mathrm{N}}$ (step 4) than in the other steps using baseline or optimized PSV mode (Steps 1, 2, 3).

Eadi PSV optimization did not modify $\mathrm{T}_{\text {iex }}$ (Fig. 2 and Additional file 3). However $T_{\text {iex }}$ was reduced during $\mathrm{PSV}_{\mathrm{N}}$ in comparison with baseline and optimized PSV mode.

Patients had very few asynchrony events. The global asynchrony indexes were not different during the four steps ((1 (0-1.5) \%; $0(0-2.5) \% ; 0(0-1) \%$; and $0(0-4)$ $\%$ in steps $1,2,3$, and 4 , respectively). Of note, two patients had a high incidence of asynchronies in $\mathrm{PSV}_{\mathrm{N}}$ (global asynchrony index of 10 and 12\% respectively) due to double triggerings (of unclear clinical significance), whereas they presented a very low incidence of asynchronies in baseline and Eadi-optimized PSV. Frequent pseudo-autotriggering were also observed in $\mathrm{PSV}_{\mathrm{N}}$ (pseudo-autotriggering asynchrony index of 4 (0.5-8.5) $\%)$. By contrast, one patient with severe restrictive disease presented severe asynchrony due to premature cyclings and double triggerings in steps 1,2 , and 3 (79, 24, and $41 \%$ respectively) but did not present any asynchrony event in step 4 (Additional file 4).

\section{Effect of PSV optimization and PSV $_{N}$ on breathing pattern, Eadi, and NVE}

Breathing pattern ( $R R, V t$, and minute ventilation), Eadi (peak and area under the curve of the Eadi) and NVE were not altered by ventilator settings modifications (Table 3 ).

Table 2 Ventilator settings during the four steps

\begin{tabular}{|c|c|c|c|c|c|}
\hline & Step 1 & Step 2 & Step 3 & Step 4 & $p$ \\
\hline Inspiratory trigger sensitivity (flow trigger) & $2(2-2)$ & $3(2-4)$ & $3(2-4)$ & - & 0.004 \\
\hline PEEP $\left(\mathrm{cmH}_{2} \mathrm{O}\right)$ & $8(5.75-8)$ & $8(5.75-8)$ & $8(7.25-9.75)$ & $8(7.25-9.75)$ & 0.007 \\
\hline PS level $\left(\mathrm{cmH}_{2} \mathrm{O}\right)$ & $9(8-10)$ & $9(8-10)$ & $9(8-10)$ & - & - \\
\hline Cycling criterion (\%) & $30(30-30)$ & $47.5(40-53.75)$ & $47.5(40-53.75)$ & - & $<0.001$ \\
\hline
\end{tabular}

Results are presented as median and interquartile range PEEP positive end expiratory pressure, $P S$ pressure support 


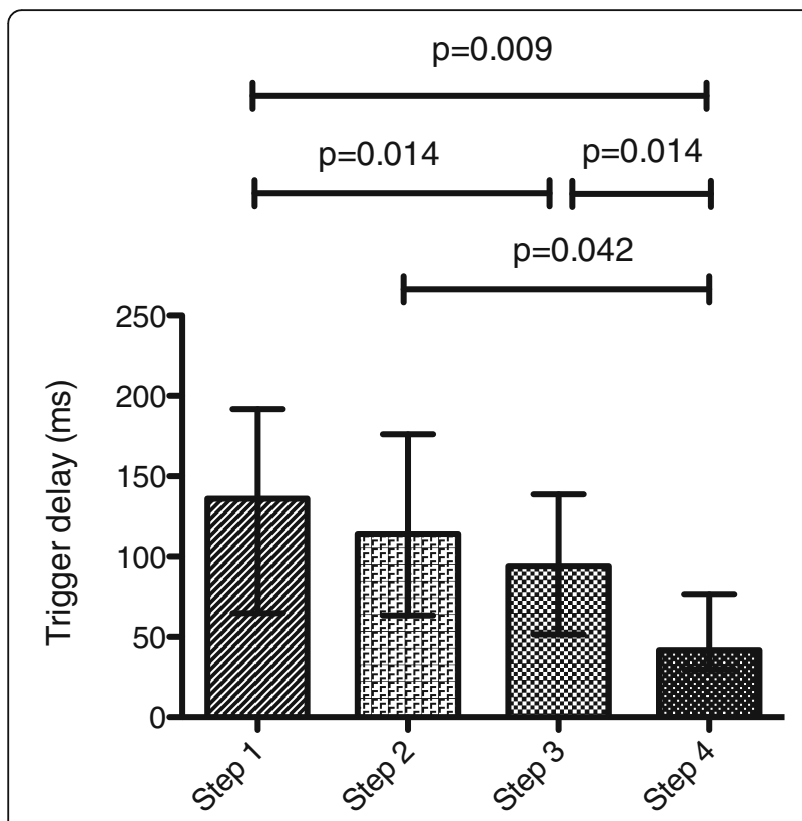

Fig. 1 Trigger delay during the four steps. Plots represent median and interquartile range (overall comparison, $p=0.002$ )

\section{Effect of PSV optimization and PSV $_{\mathrm{N}}$ on patients' effort}

The improvement in patient-ventilator interaction was not associated with changes in WOB (Fig. 3 and Additional file 5) or PTP (Fig. 4 and Additional file 5).

\section{Discussion}

The present study showed in a population of patients with few major asynchronies when ventilated using standard PSV that an Eadi-based optimization strategy allowed improving patient-ventilator interaction but with

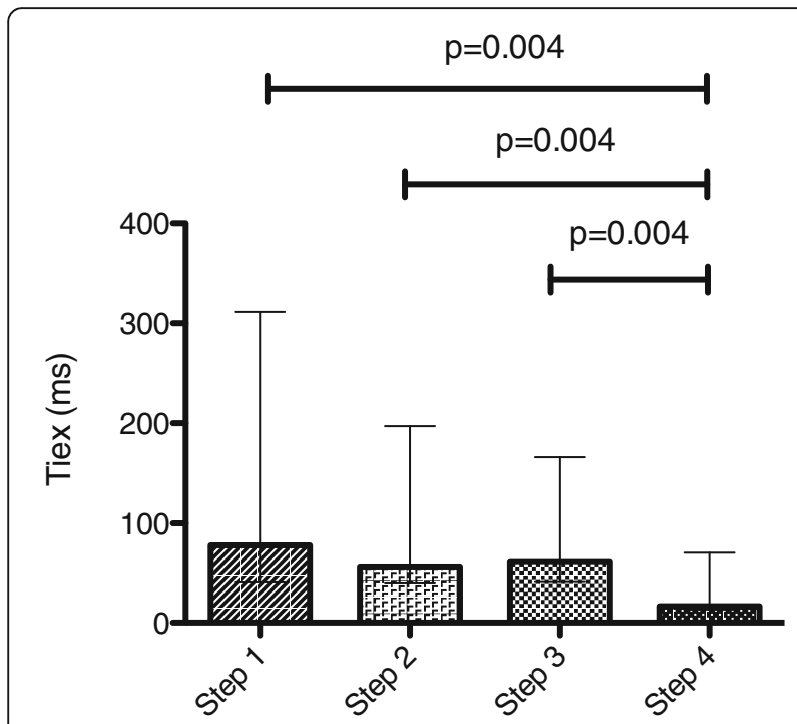

Fig. 2 Inspiratory time in excess $\left(T_{\text {iex }}\right)$ during the four steps. Plots represent median and interquartile range (overall comparison, $p=0.014$ ) minimal changes overall in breathing pattern or effort. More specifically, Eadi-optimized PSV reduced $T_{d}$ whereas Eadi-triggered and -cycled pressure assist ventilation $\left(\mathrm{PSV}_{\mathrm{N}}\right)$ further reduced $\mathrm{T}_{\mathrm{d}}$ and optimized expiratory synchrony. Thus these new alternatives to ventilate patients combine the advantage of Eadi-based trigger and cycling-off in terms of patient-ventilator synchrony and the advantage of standard PSV in terms of pressurization and clinical use for most clinicians familiar to PSV. There was no concomitant measurable change in patient effort.

Before further discussing the results, several limitations should be addressed. First, this physiological study only included 11 patients. These patients had only few major asynchronies suggesting that the ventilator settings at baseline were already well adapted and thus difficult to further optimize in terms of major asynchronies. Second, only a short period of time was observed and it cannot be excluded that different results could have been demonstrated if a prolonged period of time had been studied. However this allowed keeping patients stable enough to compare the different steps. This was demonstrated by performing step $3 \mathrm{~b}$ to rule out a time effect. Third, the offline synchrony analysis was performed manually and can sometimes be prone to interpretation. However, the reading methodology followed well-defined previously published criteria.

Optimized PSV was obtained during steps 2 and 3 using information regarding the intensity and timing of inspiratory demand coming from the brain stem respiratory centers but recorded in periphery as Eadi. Theoretically, using this information on a real-time basis should allow delivering assisted ventilation synchronized to patient demand. During step 2 Eadi was used to monitor asynchronies and to optimize ventilator settings to reduce patient-ventilator asynchronies as much as possible. As a low level of assist was set by the clinicians already trained to avoid over-assist, there were virtually no patient-ventilator major asynchronies at baseline and no pressure support level adaptation was required. By allowing seeing the duration of inspiration (and thus $\mathrm{T}_{\mathrm{iex}}$ ) at the bedside during PSV, Eadi monitoring could be used to optimize the expiratory trigger, a setting often difficult to optimize in daily practice but closely related to the occurrence of asynchronies when not optimally set $[7,29]$. Practically, in our study Eadi information led to expiratory trigger threshold changes in $82 \%$ of the subjects but did not alter $\mathrm{T}_{\text {iex }}$. Eadi was also used to optimize PEEP setting during step 3, another challenge at the bedside especially during PSV.

Eadi-triggered and -cycled assisted pressure ventilation (or $\mathrm{PSV}_{\mathrm{N}}$ ) reduces $\mathrm{T}_{\mathrm{d}}$ in comparison with both standard PSV and Eadi-optimized PSV mode using pneumatic signal. These results are consistent with previous studies performed in standard NAVA mode $[17,22,30]$ or in 
Table 3 Breathing pattern, electrical activity of the diaphragm (Eadi), and neuroventilatory efficiency (NVE) during the four steps

\begin{tabular}{|c|c|c|c|c|c|}
\hline & Step 1 & Step 2 & Step 3 & Step 4 & $p$ \\
\hline Respiratory rate (breaths. $\mathrm{min}^{-1}$ ) & $22(18-29)$ & $20(19-28)$ & $23(19-26)$ & $20(19-26)$ & 0.679 \\
\hline Tidal volume $(\mathrm{mL})$ & $432(340-521)$ & $419(336-586)$ & $442(332-582)$ & $440(340-576)$ & 0.66 \\
\hline Minute ventilation $\left(\operatorname{L} \cdot \mathrm{min}^{-1}\right)$ & $9.0(7.7-11.1)$ & $9.6(7.4-11.3)$ & $9.6(7.1-11.8)$ & $9.5(7.5-10.9)$ & 0.792 \\
\hline $\operatorname{Eadi}_{\max }(\mu \mathrm{V})$ & $18.4(10.5-25.6)$ & $18.0(12.6-21.4)$ & $21.5(14.5-23.4)$ & $16.8(14.0-22.3)$ & 0.819 \\
\hline $\operatorname{Eadi}_{A \cup C}(\mu \vee . s)$ & $11.6(6.7-17.9)$ & $9.9(8.6-13.5)$ & $13.9(9.1-16.4)$ & $11.5(8.4-14.1)$ & 0.819 \\
\hline $\operatorname{NVE}\left(m L . \mu V^{-1}\right)$ & $30.5(12.0-45.3)$ & $23.7(18.6-39.3)$ & $23.4(17.6-36.8)$ & $28.5(19.0-36.7)$ & 0.819 \\
\hline
\end{tabular}

Results are presented as median and interquartile range

Eadi $_{\text {max }}$ peak of the Eadi, Eadi ${ }_{A \cup C}$ area under the curve of the Eadi, NVE neuroventilatory efficiency

$\mathrm{PSV}_{\mathrm{N}}$ mode during invasive ventilation [31] or during helmet-delivered noninvasive ventilation $[32,33]$ and were expected, as an Eadi increase is detected earlier by the ventilator than flow or pressure changes [34] related to air motion in the lungs. Interestingly, the very short $\mathrm{T}_{\mathrm{d}}$ observed in $\operatorname{PSV}_{N}(<50 \mathrm{~ms})$ is lower than the conscious threshold of perception (about $150 \mathrm{~ms}$ ) [35], which may contribute to optimize patient comfort. In our study, as in Liu et al. data [31], $\mathrm{PSV}_{\mathrm{N}}$ allows improving $\mathrm{T}_{\text {iex }}$ in comparison with standard and Eadi-optimized PSV mode.

However, during PSV $_{\mathrm{N}}$, pseudo-autotriggerings due to very small diaphragm contraction or Eadi signal artefacts were frequent and may have led to patient discomfort. This may be related to the very high amplification provided by PSV $_{\mathrm{N}}$.

Despite the improvement in patient-ventilator interaction, WOB and PTP were not altered in Eadi-optimized PSV or PSV $\mathrm{N}_{\mathrm{N}}$. This may be explained by the low pressure support level and the low number of major asynchronies observed in the four steps. An Eadi-based optimization strategy is more likely to impact patient effort in patients with greater assistance and poorer patient-ventilator synchrony. In addition, our study illustrates that individualization of the approach is necessary since

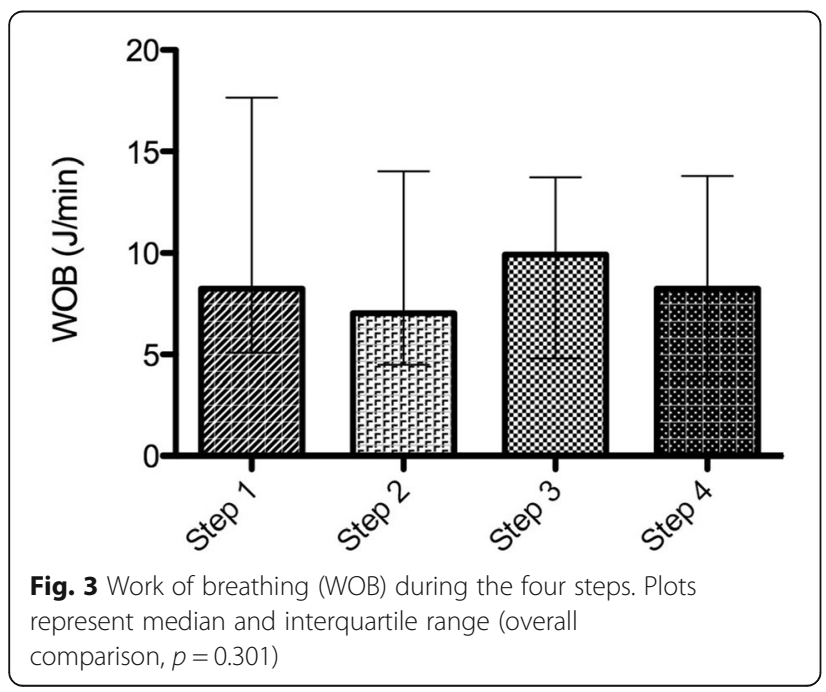

results in patients with restrictive, obstructive or obesity-associated disease may need different settings. Of note, Passath et al. demonstrated that an increase in PEEP was associated with a decrease in Eadi for large PEEP variations [36]. We did not observe any changes in Eadi when we increased PEEP in our study (step 3). This difference may be explained by the lower range of PEEP variation in our study.

Eadi-optimized PSV and $\mathrm{PSV}_{\mathrm{N}}$ allowed better patientventilator synchrony and rapid pressurization. The major advantage of using the Eadi signal in these ways is to optimize a mode of ventilation well known and familiar to all clinicians.

\section{Conclusions}

Even if the interest of optimizing $\mathrm{T}_{\mathrm{d}}$ and $\mathrm{T}_{\text {iex }}$ can be challenged from a clinical point of view in the absence of major asynchronies reduction, this study demonstrates the feasibility and interest of using Eadi recording to optimize patient ventilator interaction. Based on this result, outcome studies to assess the interest of using this strategy by default are now required before recommending this approach.

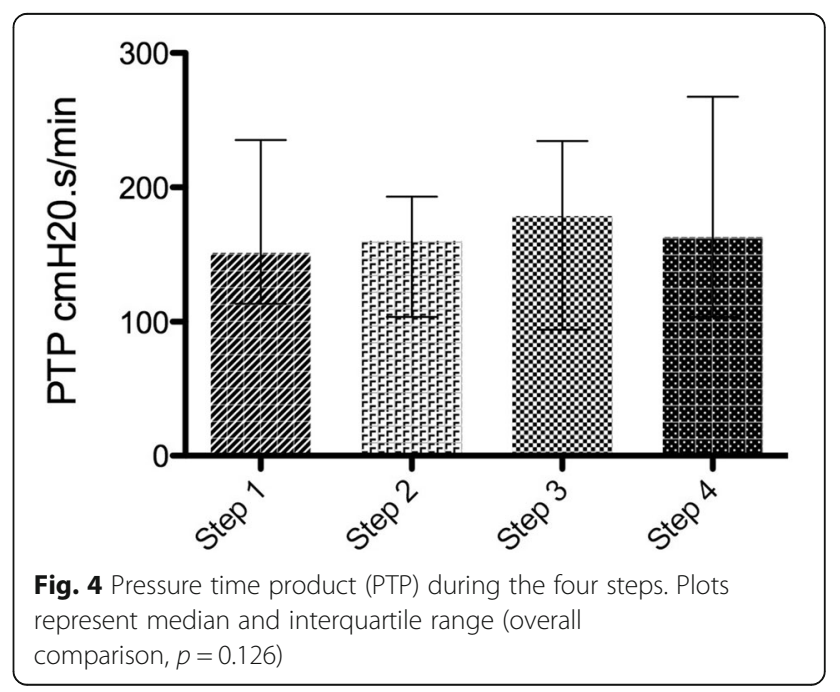




\section{Additional files}

Additional file 1: Definition of trigger delay $\left(T_{d}\right)$ and inspiratory time in excess $\left(T_{\text {iex }}\right)$. Paw, airway pressure; Eadi, electrical activity of the diaphragm. (PDF $63 \mathrm{~kb}$ )

Additional file 2: Example of pseudo-autotriggering (arrow) in Eaditriggered and cycle- assisted pressure ventilation ( P PSV $_{N}$ ) mode. Paw, airway pressure; Pes, esophageal pressure; Eadi, electrical activity of the diaphragm. Pseudo-autotriggerings are defined as a significant pressurization delivered by the ventilator not related to a patient's effort. Note the absence of deflection in esophageal pressure demonstrating the absence of patient effort. (PDF $60 \mathrm{~kb}$ )

Additional file 3: Trigger delay (A) and inspiratory time in excess $\left(T_{\text {iex }}\right)$ (B) during the four steps. Individual data. Horizontal red lines represent the median values. (PDF $45 \mathrm{~kb}$ )

Additional file 4: Airway pressure (Paw), flow, esophageal pressure (Pes) and electrical activity of the diaphragm (Eadi) tracings during the four steps in a restrictive patient. A, step 1; B, step 2; C, step 3 and D, step 4. (PDF $261 \mathrm{~kb}$ )

Additional file 5: Work of breathing (WOB) (A) and pressure time product (PTP) (B) during the four steps. Individual data. Horizontal red lines represent the median values. (PDF $45 \mathrm{~kb}$ )

\section{Abbreviations}

COPD: Chronic obstructive pulmonary disease; Eadi: Electrical activity of the

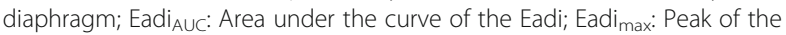
Eadi; NAVA: Neurally adjusted ventilatory assist; NVE: Neuroventilatory efficiency; Paw: Airway pressure; PEEP: Positive end-expiratory pressure; Pes: Esophageal pressure; PSV: Pressure support ventilation; PSV $V_{N}$ Neural pressure support ventilation; PTP: Pressure-time product; $T_{D}$ : Trigger delay $\mathrm{T}_{\text {iex: }}$ Inspiratory time in excess; Vt: Tidal volume; WOB: Work of breathing

\section{Acknowledgements}

The authors thank Rabbia Waheed for considerable help with the measurements, and the personnel of the medical-surgical ICU for their continuous support during the study.

\section{Funding}

FB was receiving a grant from his home institution in France. NR was receiving a grant from his home institution in Thailand.

\section{Availability of data and materials}

The data that support the findings of this study are available from the corresponding author upon reasonable request.

\section{Authors' contributions}

$F B, L P, N R, C S, H R$, and $L B$ contributed to the conception and design of the study. FB and NR performed the acquisition of data. All authors contributed to the analysis and interpretation of data, wrote and approved the final manuscript.

\section{Competing interests}

LP has given talks in symposia organized by Maquet and Hamilton Medical and has received compensation for related travel and accommodation fees. CS receives royalties and is consulting to Maquet Critical Care for patents owned by St Michael's Hospital. HR has given talks in symposia organized by Maquet and received compensation for travel and accommodation fees. LB's laboratory has received research grants or equipment from the following companies: Covidien (PAV), General Electric (lung volume measurement), Air Liquide (CPR), Philips (sleep), Fisher Paykel (high-flow). LB has received consultant fees from Covidien. The authors declare that they have no competing interests.

\section{Consent for publication}

Not applicable.

\section{Ethical approval and consent to participate}

The study was approved by an independent review board (St Michael's Hospital Ethics Committee, REB\# 13-363). Written informed consent was obtained from the patient or next of kin before inclusion in the study.

\section{Author details}

${ }^{1}$ Interdepartmental Division of Critical Care Medicine, University of Toronto, Toronto, ON, Canada. ${ }^{2}$ Keenan Research Centre and Li Ka Shing Knowledge Institute, St. Michael's Hospital, 30 Bond St, Toronto, ON M5B 1W8, Canada. ${ }^{3}$ Medical Intensive Care Unit, Hospital of Angers, University of Angers, Angers, France. ${ }^{4}$ Adult Intensive Care and Burn Unit, University Hospital of Lausanne (CHUV), Lausanne, Switzerland. ${ }^{5}$ Division of Respiratory Diseases and Tuberculosis, Department of Medicine, Faculty of Medicine Siriraj Hospital, Bangkok, Thailand. ${ }^{6} \mathrm{CHU}$ de Bordeaux, Service d'Anesthesie-Reanimation 2, Pessac 33600, France.

Received: 3 October 2016 Accepted: 4 January 2017

Published online: 31 January 2017

\section{References}

1. Russell WC, Greer JR. The comfort of breathing: a study with volunteers assessing the influence of various modes of assisted ventilation. Crit Care Med. 2000;28:3645-8.

2. Girard TD, Kress JP, Fuchs BD, Thomason JWW, Schweickert WD, Pun BT, et al. Efficacy and safety of a paired sedation and ventilator weaning protocol for mechanically ventilated patients in intensive care (Awakening and Breathing Controlled trial): a randomised controlled trial. Lancet. 2008;371: 126-34.

3. Jaber S, Jung B, Matecki S, Petrof BJ. Clinical review: ventilator-induced diaphragmatic dysfunction-human studies confirm animal model findings! Crit Care Lond Engl. 2011;15:206

4. Futier E, Constantin J-M, Combaret L, Mosoni L, Roszyk L, Sapin V, et al. Pressure support ventilation attenuates ventilator-induced protein modifications in the diaphragm. Crit Care Lond Engl. 2008;12:R116.

5. Maclntyre N, Nishimura M, Usada Y, Tokioka H, Takezawa J, Shimada Y. The Nagoya conference on system design and patient-ventilator interactions during pressure support ventilation. Chest. 1990;97:1463-6.

6. Tobin MJ, Jubran A, Laghi F. Patient-ventilator interaction. Am J Respir Crit Care Med. 2001;163:1059-63.

7. Yamada Y, Du HL. Analysis of the mechanisms of expiratory asynchrony in pressure support ventilation: a mathematical approach. J Appl Physiol. 2000; $88 \cdot 2143-50$

8. Thille AW, Rodriguez P, Cabello B, Lellouche F, Brochard L. Patient-ventilator asynchrony during assisted mechanical ventilation. Intensive Care Med. 2006:32:1515-22.

9. Doorduin J, Sinderby CA, Beck J, van der Hoeven JG, Heunks LMA. Automated patient-ventilator interaction analysis during neurally adjusted non-invasive ventilation and pressure support ventilation in chronic obstructive pulmonary disease. Crit Care Lond Engl. 2014;18:550.

10. Kondili E, Prinianakis G, Georgopoulos D. Patient-ventilator interaction. Br J Anaesth. 2003;91:106-19.

11. De Wit M, Pedram S, Best AM, Epstein SK. Observational study of patientventilator asynchrony and relationship to sedation level. J Crit Care. 2009;24: $74-80$.

12. Chao DC, Scheinhorn DJ, Stearn-Hassenpflug M. Patient-ventilator trigger asynchrony in prolonged mechanical ventilation. Chest. 1997;112:1592-9.

13. Blanch L, Villagra A, Sales B, Montanya J, Lucangelo U, Luján M, et al. Asynchronies during mechanical ventilation are associated with mortality. Intensive Care Med. 2015:41:633-41.

14. Thille AW, Cabello B, Galia F, Lyazidi A, Brochard L. Reduction of patientventilator asynchrony by reducing tidal volume during pressure-support ventilation. Intensive Care Med. 2008;34:1477-86.

15. Nava S, Bruschi C, Rubini F, Palo A, lotti G, Braschi A. Respiratory response and inspiratory effort during pressure support ventilation in COPD patients. Intensive Care Med. 1995;21:871-9.

16. Colombo D, Cammarota G, Alemani M, Carenzo L, Barra FL, Vaschetto R, et al. Efficacy of ventilator waveforms observation in detecting patientventilator asynchrony. Crit Care Med. 2011:39:2452-7.

17. Piquilloud L, Vignaux L, Bialais E, Roeseler J, Sottiaux T, Laterre P-F, et al. Neurally adjusted ventilatory assist improves patient-ventilator interaction. Intensive Care Med. 2011;37:263-71. 
18. Demoule A, Clavel M, Rolland-Debord C, Perbet S, Terzi N, Kouatchet A, et al. Neurally adjusted ventilatory assist as an alternative to pressure support ventilation in adults: a French multicentre randomized trial. Intensive Care Med. 2016:42:1723-32.

19. Carteaux G, Córdoba-Izquierdo A, Lyazidi A, Heunks L, Thille AW, Brochard L. Comparison between neurally adjusted ventilatory assist and pressure support ventilation levels in terms of respiratory effort. Crit Care Med. 2016; 44:503-11.

20. Baydur A, Behrakis PK, Zin WA, Jaeger M, Milic-Emili J. A simple method for assessing the validity of the esophageal balloon technique. Am Rev Respir Dis. 1982;126:788-91.

21. Akoumianaki E, Maggiore SM, Valenza F, Bellani G, Jubran A, Loring SH, et al. The application of esophageal pressure measurement in patients with respiratory failure. Am J Respir Crit Care Med. 2014;189:520-31.

22. Piquilloud L, Tassaux D, Bialais E, Lambermont B, Sottiaux T, Roeseler J, et al. Neurally adjusted ventilatory assist (NAVA) improves patient-ventilator interaction during non-invasive ventilation delivered by face mask. Intensive Care Med. 2012;38:1624-31.

23. Vitacca M, Bianchi L, Zanotti E, Vianello A, Barbano L, Porta R, et al. Assessment of physiologic variables and subjective comfort under different levels of pressure support ventilation. Chest. 2004;126:851-9.

24. L'Her E, Deye N, Lellouche F, Taille S, Demoule A, Fraticelli A, et al. Physiologic effects of noninvasive ventilation during acute lung injury. Am J Respir Crit Care Med. 2005;172:1112-8.

25. Cabello B, Mancebo J. Work of breathing. Intensive Care Med. 2006;32:1311-4.

26. Sassoon CS, Light RW, Lodia R, Sieck GC, Mahutte CK. Pressure-time product during continuous positive airway pressure, pressure support ventilation, and T-piece during weaning from mechanical ventilation. Am Rev Respir Dis. 1991;143:469-75.

27. Bonmarchand G, Chevron V, Chopin C, Jusserand D, Girault C, Moritz F, et al. Increased initial flow rate reduces inspiratory work of breathing during pressure support ventilation in patients with exacerbation of chronic obstructive pulmonary disease. Intensive Care Med. 1996;22:1147-54.

28. Bonmarchand G, Chevron V, Ménard JF, Girault C, Moritz-Berthelot F, Pasquis $P$, et al. Effects of pressure ramp slope values on the work of breathing during pressure support ventilation in restrictive patients. Crit Care Med. 1999:27:715-22.

29. Tassaux D, Gainnier M, Battisti A, Jolliet P. Impact of expiratory trigger setting on delayed cycling and inspiratory muscle workload. Am J Respir Crit Care Med. 2005;172:1283-9.

30. Spahija J, de Marchie M, Albert M, Bellemare P, Delisle S, Beck J, et al. Patient-ventilator interaction during pressure support ventilation and neurally adjusted ventilatory assist. Crit Care Med. 2010;38:518-26.

31. Liu L, Xia F, Yang Y, Longhini F, Navalesi P, Beck J, et al. Neural versus pneumatic control of pressure support in patients with chronic obstructive pulmonary diseases at different levels of positive end expiratory pressure: a physiological study. Crit Care Lond Engl. 2015;19:244.

32. Moerer O, Beck J, Brander L, Costa R, Quintel M, Slutsky AS, et al. Subjectventilator synchrony during neural versus pneumatically triggered noninvasive helmet ventilation. Intensive Care Med. 2008:34:1615-23.

33. Cammarota G, Longhini F, Perucca R, Ronco C, Colombo D, Messina A, et al. New setting of neurally adjusted ventilatory assist during noninvasive ventilation through a helmet. Anesthesiology. 2016;125(6):1181-9.

34. Sinderby C, Navalesi P, Beck J, Skrobik Y, Comtois N, Friberg S, et al. Neural control of mechanical ventilation in respiratory failure. Nat Med. 1999;5: 1433-6.

35. Whitelaw WA, Derenne JP, Milic-Emili J. Occlusion pressure as a measure of respiratory center output in conscious man. Respir Physiol. 1975;23:181-99.

36. Passath C, Takala J, Tuchscherer D, Jakob SM, Sinderby C, Brander L. Physiologic response to changing positive end-expiratory pressure during neurally adjusted ventilatory assist in sedated, critically ill adults. Chest. 2010; 138:578-87.

\section{Submit your next manuscript to BioMed Central and we will help you at every step:}

- We accept pre-submission inquiries

- Our selector tool helps you to find the most relevant journal

- We provide round the clock customer support

- Convenient online submission

- Thorough peer review

- Inclusion in PubMed and all major indexing services

- Maximum visibility for your research

Submit your manuscript at www.biomedcentral.com/submit

) Biomed Central 